\title{
Minimally invasive lumbar decompression: a review of indications, techniques, efficacy and safety
}

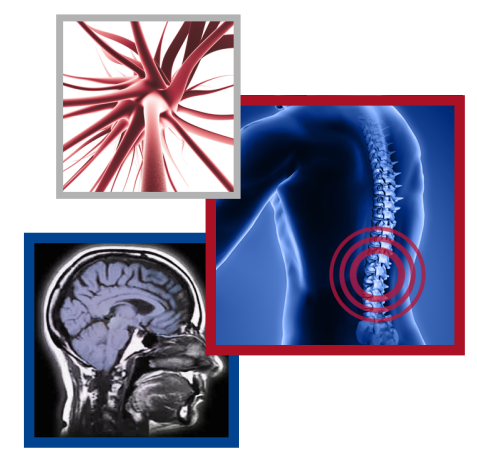

Sameer Jain**, ${ }^{*}$, Timothy Deer ${ }^{\ddagger}$, Dawood Sayed ${ }^{3}$, Pooja Chopra ${ }^{4}$, Sayed Wahezi ${ }^{5}$, Navdeep Jassal ${ }^{6}$, Jackie Weisbein ${ }^{7}$, Jessica Jameson ${ }^{8}$, Mark Malinowski ${ }^{9}$ \& Stanley Golovac ${ }^{10}$

${ }^{1}$ Pain Treatment Centers of America, Little Rock, AR 72211, USA

${ }^{2}$ The Spine \& Nerve Center of The Virginias, Charleston, WV 25301, USA

${ }^{3}$ University of Kansas Hospital, Kansas City, KS 66160, USA

${ }^{4}$ The University of Texas MD Anderson Cancer Center, Houston, TX 77030, USA

${ }^{5}$ Montefiore Medical Center, Albert Einstein College of Medicine, Bronx, NY 10461, USA

${ }^{6}$ Spine \& Pain Institute of Florida, Lakeland, FL 33805, USA

${ }^{7}$ Napa Valley Orthopaedic Medical Group, Napa, CA 94558, USA

${ }^{8}$ Axis Spine Center, Coeur d'Alene, ID 83815, USA

${ }^{9}$ Adena Health System, Chillicothe, OH 45601, USA

${ }^{10}$ Florida Pain Institute, Melbourne, FL 32940, USA

*Author for correspondence: paindocsj@gmail.com

${ }^{\ddagger}$ Authors contributed equally

\section{Practice points}

- Neurogenic claudication due to lumbar spinal stenosis presents most commonly as gluteal or leg pain with walking or standing that is alleviated with sitting.

- A major cause of lumbar spinal stenosis is ligamentum flavum hypertrophy (LFH), which contributes up to $85 \%$ of spinal canal narrowing.

- The mild $^{\circledR}$ procedure debulks LFH with a goal of relieving symptoms of neurogenic claudication.

- Patients with LFH and multiple other spinal comorbidities, including lateral and foraminal stenosis, have shown significant improvement in mobility and pain after the mild procedure.

- mild candidates must present with neurogenic claudication, and stenosis must be confirmed on imaging with ligamentum flavum $\geq 2.5 \mathrm{~mm}$.

- The mild procedure is performed percutaneously through a 5.1-mm port with specially designed minimally invasive instruments and can be done unilaterally or bilaterally, and at multiple levels, leaving no implants behind.

- mild has been shown to be as safe as an epidural steroid injection.

- Following treatment with mild, patients typically resume normal activity within $24 \mathrm{~h}$ with no restrictions.

- Thirteen clinical studies, including two level 1 randomized controlled trials, have demonstrated statistically significant improvement in pain and mobility, and superiority of mild versus epidural steroid injections.

Lumbar spinal stenosis is a common degenerative spine condition. In properly selected patients, minimally invasive lumbar decompression (mild ${ }^{\circledR}$ ) may be an option to improve outcomes. This review provides an in-depth description of the mild procedure and a comprehensive examination of safety and efficacy. Two randomized controlled trials, together with 11 other controlled clinical studies, have established the efficacy of mild, which is a minimally invasive procedure that does not involve implants and has demonstrated excellent efficacy and safety. With an established safety profile equivalent to epidural steroid injections, and efficacy that has been shown to be superior to such injections, mild can reasonably be positioned early in the treatment algorithm for these patients. Based on extensive review of the literature, robust safety and efficacy through 2 years, and in accordance with minimally invasive spine treatment guidelines, mild is recommended as the first intervention after failure of conservative measures for lumbar spinal stenosis patients with neurogenic claudication and ligamentum flavum hypertrophy.

First draft submitted: 21 May 2020; Accepted for publication: 16 June 2020; Published online:

1 July 2020

Keywords: ligamentum flavum hypertrophy $\bullet$ lumbar spinal stenosis $\bullet$ mild ${ }^{\circledR} \bullet$ minimally invasive lumbar decompression • neurogenic claudication • review 
Lumbar spinal stenosis (LSS) is a common degenerative spinal condition causing significant pain and functional disability, especially in the elderly. In 1976, Arnoldi et al. first defined LSS as any type of narrowing of the spinal canal, nerve root canals or intervertebral foramina [1]. The North American Spine Society clinical guideline development group has now defined LSS as "a condition in which there is diminished space available for the neural and vascular elements in the lumbar spine secondary to degenerative changes in the spinal canal' [2]. LSS may be congenital in nature or may be acquired over the years secondary to degenerative spine disease. Anteriorly, disc degeneration is a common cause, whereas posterior to the spinal canal, facet arthropathy and ligamentum flavum hypertrophy (LFH) are contributing causes of spinal stenosis. The prevalence of acquired LSS is estimated to be around $4 \%$ of the population under the age of 40 years old; however, it increases to approximately $19.4 \%$ in the 60-69-year-old age group [3]. Even though most LSS sufferers are asymptomatic, $10 \%$ of the population develop symptoms related to LSS by the age of 70 years old [4]. When symptomatic, LSS manifests itself with a constellation of clinical symptoms characterized by neurogenic claudication. The most common presentation of neurogenic claudication includes gluteal and/or leg pain, numbness, weakness, or fatigue with walking or standing that is alleviated with sitting and/or lumbar flexion [5].

Historically, definitive treatment of spinal stenosis has been decompressive surgery, which exposes patients to complications, extensive recovery periods and an economic healthcare burden. Conservative measures have been trialed, including physical therapy, NSAIDs and other pharmacological agents including calcitonin and prostaglandin E1 derivatives with limited benefit [6]. Epidural steroid injections (ESIs) may provide some symptomatic relief for a short period of time; however, this treatment modality has shown to be ineffective in treating patients with neurogenic claudication over a longer follow-up period $[7,8]$. Spinal cord stimulation is another treatment modality that has been attempted for the treatment of spinal stenosis, but it lacks robust evidence in favor of its use. Over the past decade, more minimally invasive therapies for the treatment of spinal stenosis have been assessed and corroborated by prospective, randomized trials. These include percutaneous image-guided lumbar decompression (PILD) and interspinous spacers [9].

This review will focus on the only commercially available PILD treatment option - mild ${ }^{\circledR}$ (minimally invasive lumbar decompression, Vertos Medical, CA, USA), a technique developed for the treatment of central stenosis of the lumbar region secondary to LFH. Preprocedural considerations, the technique, scientific evidence and comparative safety to other treatment modalities are described.

\section{Ligamentum flavum hypertrophy}

The ligamentum flavum (LF) is a thick ligament connecting the adjacent vertebrae from C2 to S1. It is a welldefined elastic structure that consists of elastic (80\%) and collagen (20\%) fibers [10]. The high elastic fiber content imparts its yellow color and is also referred to as the yellow ligament. However, with consistent wear and tear, LF becomes hypertrophied and results in lumbar spinal canal stenosis (LSCS) and its associated symptoms. This phenomenon was first described by Elsberg in 1913 [11]. Since then, LFH has been identified as a major cause of LSCS and can contribute to between 50 and $85 \%$ of spinal canal narrowing [12].

\section{Pathogenesis}

Hypertrophy and fibrosis of the LF has been attributed to the aging process and mechanical stress endured by the spine; however, the exact pathogenesis of LFH is still unknown. Yong-Hing et al. noted that the normal LF consists of $80 \%$ elastic fibers and $20 \%$ collagen fibers, but in spondylotic specimens, the content varies from 50 to $80 \%$ elastin and 20 to $50 \%$ collagen [13]. Multiple theories have been proposed to account for this phenomenon. Chen $e t$ al. reported results from their study documenting upregulation of miR-155 in patients with LFH, which increased the expression of types I and III collagen in fibroblasts from LF [14]. Honsawek et al. demonstrated a correlation between LFH and greater bFGF expression but failed to establish causation [15]. In recent years, the role of TGF- $\beta 1$ has been suggested $[16,17]$. Another popular opinion is that angiogenesis represents a key step in the pathogenesis that follows mechanical stress during LFH development, and VEGF may play an important part in this process [18]. 


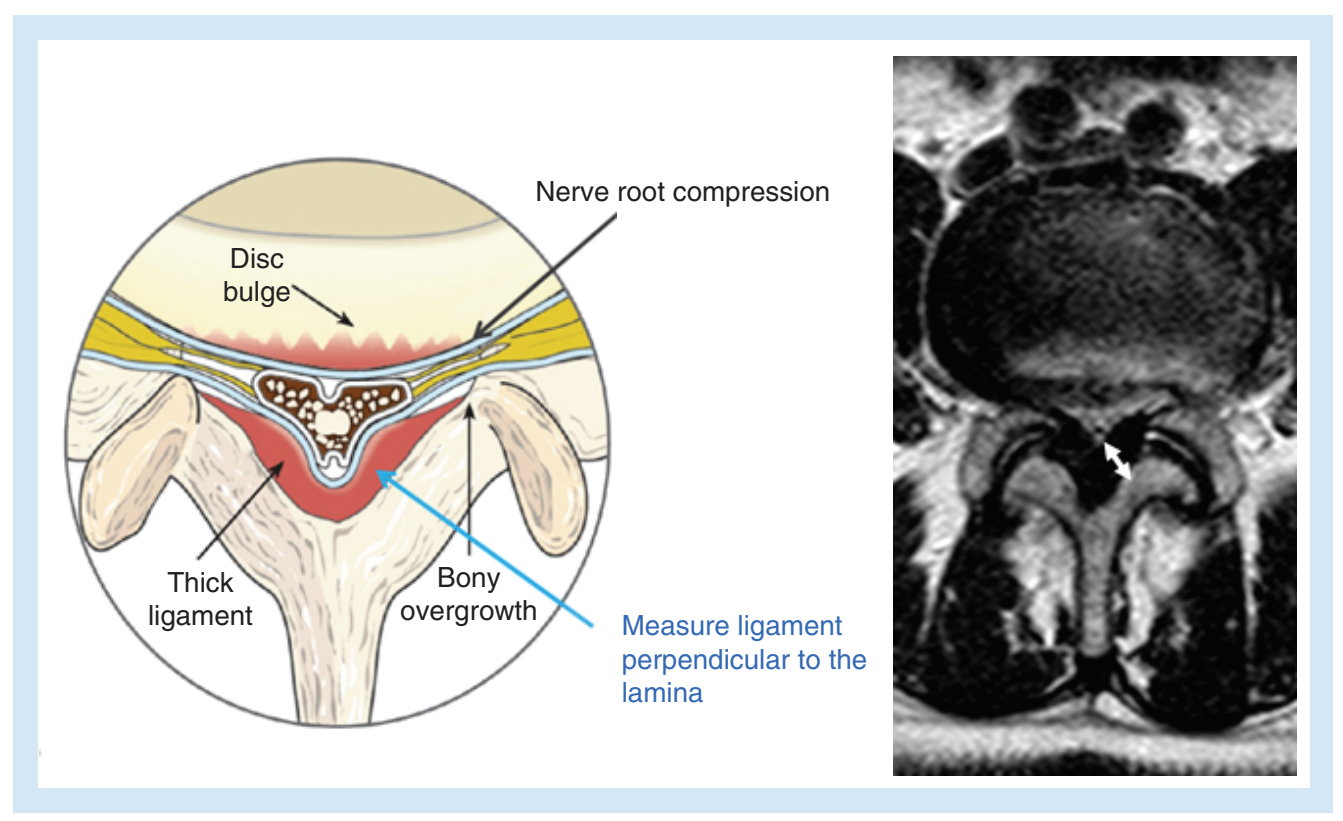

Figure 1. Axial cross-section of spinal cord depicting ligamentum flavum hypertrophy. (A) LF thickness (AP) measured perpendicular to the border of the lamina corresponding to the intervertebral disc. (B) MRI cross-sectional image demonstrating LSCS. Arrow demonstrates LFH measurement.

\section{Diagnosis}

Currently, magnetic resonance imaging (MRI), computed tomography (CT) and CT myelography are predominantly used for the diagnosis of LFH. MRI is the most commonly used modality due to its capability of yielding soft tissue contrast. CT and CT myelography may be utilized when there is a contraindication to performing MRI $[19,20]$. Although plain radiographs do not offer value in identifying LFH, they are an important tool in the assessment of spinal alignment and diagnosis of spondylolisthesis.

LF thickening is measured perpendicular to the border of the lamina corresponding to the intervertebral disc (Figure 1). The LF is hypertrophied if the thickness is $\geq 2.5 \mathrm{~mm}$. However, the thickness of the LF does not correlate with the patient being symptomatic [21]. LF thickening is most commonly seen at L3-4 and L4-5 levels; more so than at L5-S1. LFH primarily results in central, foraminal and lateral recess stenosis.

\section{Minimally invasive lumbar decompression: mild \\ History of the procedure}

The mild procedure was developed by Dr David Solsberg and Dr Donald Schomer in 2005 as a system to help treat cancer patients who developed spinal stenosis but were not able to tolerate spine surgery secondary to comorbidities. It was originally named the X-Sten mild Tool Kit and received 510(k) clearance from the US FDA on 19 December 2006. The first patient was treated immediately following FDA clearance. Within a few years of its introduction, 12 clinical studies were completed that demonstrated the efficacy of the procedure. In 2016, 1-year results of the MiDAS ENCORE randomized controlled trial (RCT) reported that mild was statistically superior to ESIs in the treatment of select LSS patients. Following publication of this level 1 evidence, the US Centers for Medicare and Medicaid Services approved nationwide Medicare coverage of mild in 2017 [22].

\section{Preoperative considerations \& patient selection}

To determine patient candidacy for the mild procedure, it is important to establish the diagnosis and etiology of LSS. History and physical examination of the patient establishes the diagnosis of symptomatic LSS, and etiology is primarily confirmed with imaging modalities. The most consistent finding of symptomatic spinal stenosis is the presence of neurogenic claudication, which includes little or no pain at rest and when sitting or lying in a recumbent position. However, upon standing or walking, these patients experience progressive back, buttock and/or 
leg pain that may have a neuropathic (numbness and tingling) and mechanical (aching) component. This pain typically resolves within a short time after sitting or lying down.

Medical history is typically more sensitive than physical examination in determining the presence of LSS. Physical examination, including motor, sensory and reflex testing, is usually normal in such patients. Certain physical examination findings may be present in some patients, such as loss of normal lumbar lordosis that becomes evident if patients walk in a forward flexed position. The most common motor finding in LSS is weakness in L5 distribution (extensor hallucis longus), although asymmetric reflexes at the knee and ankle may also be present.

Once medical history and physical examination findings are suggestive of LSS, appropriate imaging is obtained to confirm the diagnosis and etiology of stenosis. MRI of the lumbar spine is the recommended imaging modality for such patients. If MRI is contraindicated, CT myelography/CT may also be used. The most common cut-off point for central canal stenosis is an anteroposterior (AP) diameter of the central canal $<10 \mathrm{~mm}$ and/or cross-sectional area $<100 \mathrm{~mm}^{2}$ [23].

Suggested criteria for lateral stenosis include lateral recess height $<2 \mathrm{~mm}$ and lateral recess depth $<2-3 \mathrm{~mm}$. Once the presence of stenosis is confirmed, its etiology must also be established. Only when LFH (LF $\geq 2.5 \mathrm{~mm}$ ) is determined to be one of the causes of stenosis is the patient a candidate for the mild procedure. Spinal instability may also be assessed on imaging as open decompression/fusion is recommended in the presence of spondylolisthesis greater than grade II. Flexion/extension radiographs may be helpful in assessing spinal instability in such patients.

To summarize, all of the following inclusion criteria must be met for the patient to be a candidate for the mild procedure:

- Symptomatic LSS (i.e., presence of neurogenic claudication);

- Confirmation of stenosis on imaging;

- $\mathrm{LFH}(\mathrm{LF} \geq 2.5 \mathrm{~mm})$.

The following contraindications must be accounted for before the procedure is performed on the patient: Absolute contraindications:

- Prior spine surgery at the intended level of treatment;

- Presence of localized site of infection at the site of procedure.

Relative contraindications:

- Presence of higher than grade II spondylolisthesis;

- Presence of bleeding diatheses/coagulation disorder;

- Presence of systemic infection.

Technique

Minimally invasive lumbar decompression is a procedure designed to debulk hypertrophied LF with a goal of relieving neural compression causing symptoms of neurogenic claudication. mild selectively removes small portions of ligament and leaves no implants behind. The procedure is performed percutaneously through a 5.1-mm port with specially designed, minimally invasive instruments. Careful review of cross-sectional images of the index level (MRI or CT) allows assessment of the available epidural space, thickness of the LF, potential mechanical impediments to instrument entry and angles of lamina entry (Figure 2).

After a thorough evaluation of imaging, the patient is placed in prone position with a bolster or other positioning aid to reduce lumbar lordosis at the index level. This allows for increased spacing of the lamina and facilitates entry of the working instruments.

The procedure can be done unilaterally or bilaterally, and at multiple symptomatic levels. A working safety barrier is established with either an epidurogram or use of bony landmarks. If using an epidurogram, a baseline preoperative film in all views, including the contralateral oblique view, is obtained (Figure 3). Alternatively, bony landmarks can be used to identify the ventral interlaminar line. The working fluoroscopic angle for the procedure is a contralateral oblique view. The AP image is obtained to ensure that the vertebral bodies of the index level are squared off to best visualize the lamina (Figure 4).

A spinal needle is inserted on the lamina at a pitch commensurate with the sagittal pitch of the index lamina and lateral edge of the spinous process of the inferior lamina, and local anesthesia is used to anesthetize the track 


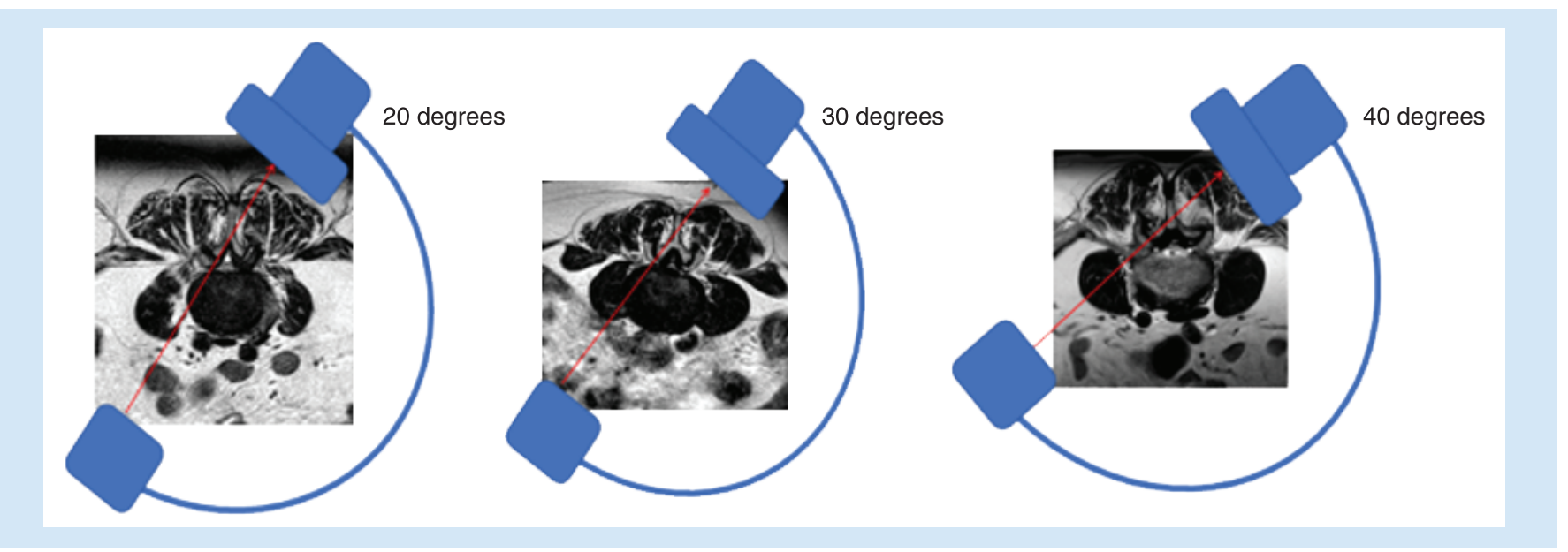

Figure 2. Pitch of lamina determines the working angle (A-C).
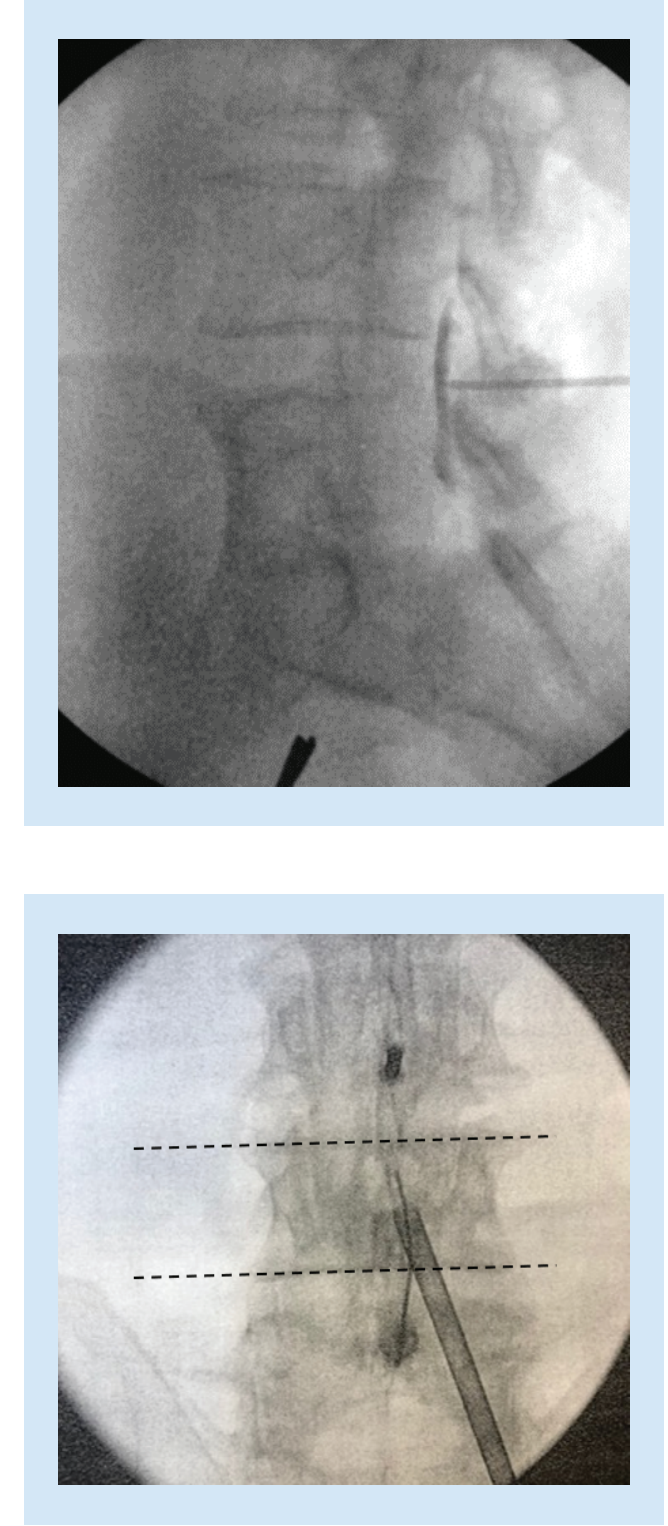

Figure 3. Preoperative epidurogram establishes a baseline for evaluating the epidural space and creating a safe visual field to direct the operative devices.
Figure 4. An AP image with the vertebral endplates squared with the fluoroscopic beam is recommended to evaluate the interlaminar space. 

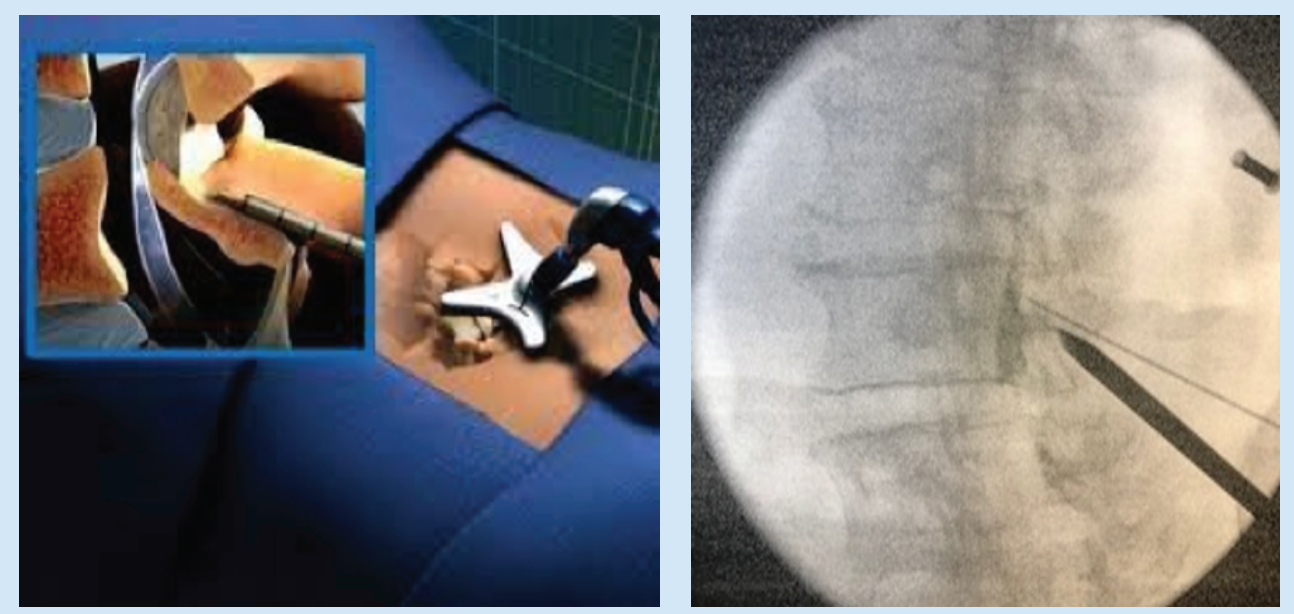

Figure 5. mild portal stabilizer that mitigates ventral migration of the operating devices while allowing for superior and inferior movement to sculpt the interlaminar space.

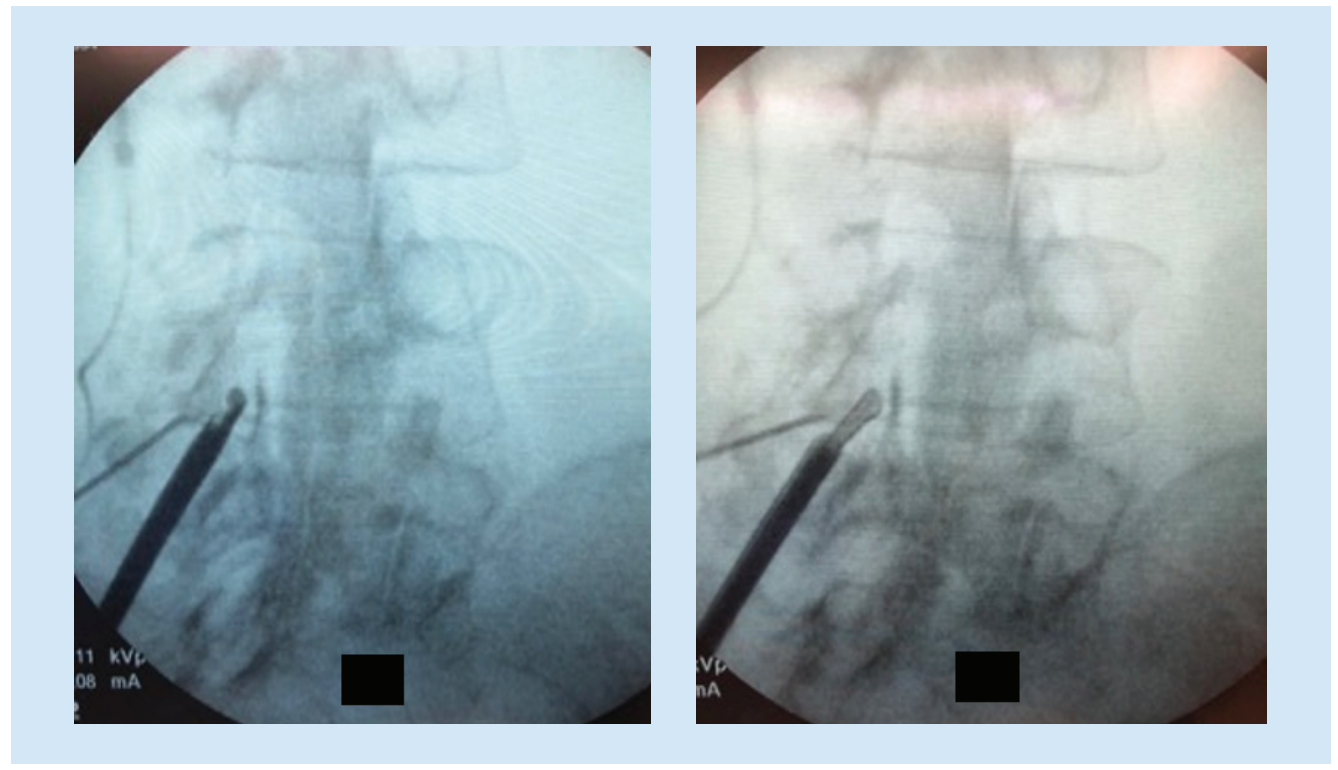

Figure 6. Images demonstrating a deployed bone rongeur (A) and tissue sculptor (B) between the lamina and within the epidural space.

and the treatment area. The mild trocar/cannula is advanced along the previously made track to rest on the inferior lamina. The contralateral oblique view is again obtained when the mild trocar contacts the superior lamina. A mild portal stabilizer is placed on the patient, and the portal is locked in this device (Figure 5).

The trocar is then removed, and the depth guide is clicked onto the top of the portal. The bone rongeur is used to remove biopsy-sized fragments of bone for the purpose of widening the interlaminar space to allow further advancement of the mild cannula. This usually requires three passes at the superior lamina and three passes at the inferior lamina. Selective removal of small amounts of lamina should be continued until interlaminar access is achieved. The bone rongeur can be rotated in 360 degrees to enhance dissection. Once the tip of the cannula is placed in the middle of the lamina on the contralateral view, the tissue sculptor is used to remove small sections of LF (Figure 6). Approximately three sets of three passes with the tissue sculptor are required for proper debulking. 
When there is no longer material to debulk and the instrument 'falls in the channel' created by the decompression, the procedure is complete.

The procedure is then performed at the opposite side, and other levels, if appropriate. Following treatment with mild, patients typically resume normal activity within $24 \mathrm{~h}$ with no restrictions and begin prescribed physical therapy at 2 weeks post procedure.

\section{Discussion}

Neurogenic claudication secondary to spinal stenosis is a common condition in the adult population. Although several conservative measures including ESIs have been tried in the past, their efficacy in managing this condition is limited [8]. PILD provides a safe and effective method for the treatment of such patients. It involves decompression of the posterior elements of the spine (lamina and LF) in a minimally invasive fashion and leaves no implants behind. Currently, mild is the only commercially available PILD device.

To date, there have been two level 1 RCTs, five prospective studies, two meta-analyses, four retrospective studies, and three case series published demonstrating the safety and efficacy of the mild procedure in treatment of LSS secondary to LFH (Table 1). All of these studies have demonstrated efficacy of this procedure in decreasing the symptoms of neurogenic claudication and have shown significant improvements in physical functionality, mobility and disability seen with this condition. Specifically, the ENCORE RCT provided level 1 evidence of the statistical superiority of mild versus ESIs in the treatment of patients with neurogenic claudication and LFH at 1-year follow-up [22]. The ENCORE Investigators also reported excellent long-term durability of the mild procedure with all outcome measures exhibiting clinically meaningful and statistically significant improvement from baseline through 6-month, 1- and 2-year follow-ups [24]. At 2 years, ENCORE Numeric Pain Rating Scale responders improved by 5 points. Mekhail et al. at Cleveland Clinic conducted a study focused on functional outcomes including Standing time and walking distance. At 1 year, walking distance increased 16-fold from 246 feet to 3956 feet, and standing time increased sevenfold from 8 to 56 min [25].

The mild clinical studies have adequately demonstrated its effectiveness in treating symptoms secondary to neurogenic claudication - even in patients with multiple types of stenosis and comorbidities. Although it has been reported that LFH contributes up to $85 \%$ of central canal narrowing and hypertrophied ligament plays a dominant role in the load-induced narrowing of the lumbar spine [12], other types of stenosis and spinal comorbidities are also common. In the ENCORE study, only 5\% of patients presented with central canal stenosis alone, and 95\% of patients presented with five or more spinal comorbidities. mild has established excellent efficacy in the presence of multiple other comorbidities, as well as lateral and foraminal stenosis. The mild procedure removes the problem in the form of hypertrophied ligament and leaves no implants behind. This success is likely related to the fact that although small increments in LFH may cause painful compression of the spinal cord, conversely very small amounts of LF removal can significantly and broadly decrease pain in these patients [25]. This may be analogous to the study published by Choy et al. who demonstrated that a small decrease in disc volume can result in large change in intradiscal pressure resulting in relief of discogenic low back pain [42].

These studies have also shown that the mild procedure is as safe as an ESI, with minimal complications and durable effect. mild offers a minimally invasive solution for a broad range of LSS patients suffering from neurogenic claudication with multiple comorbidities in addition to LFH. Further, in certain patient populations, such as those with severe osteoporosis where an interspinous spacer may be contraindicated and lumbar fusion carries the risk of cage subsidence and pedicle screw loosening [43], the mild procedure is an effective and safe alternative. In addition, mild may be the only available treatment option for patients with L5-S1 stenosis secondary to LFH who are not candidates for spinal surgery. Almost all clinical studies for mild assessed patients for procedure-related complications including dural tears, nerve root injuries, bleeding, infections and rehospitalization post procedure. Direct procedure-related complications were reported to be minimal and included soreness at the surgical site [28], minor postoperative bleeding [27] and minor intraoperative bleeding that was controlled with gel foam [22]. Even though there are no direct comparative safety studies available between mild and other decompression procedures (interspinous spacers, surgical decompression and lumbar fusion), pooled data from various studies suggest that mild is the safest among these procedures with minimal complications (Table 2) [24].

Although the mild procedure is an attractive alternative to other decompression procedures, it is not without its limitations/disadvantages (Table 3). mild cannot be performed at the site of previous spine surgery. In addition, it is used to treat spinal stenosis secondary to LFH and does not directly treat stenosis secondary to other etiologies such as disc prolapse or facet hypertrophy, in the absence of LFH. However, presence of other spinal comorbidities 


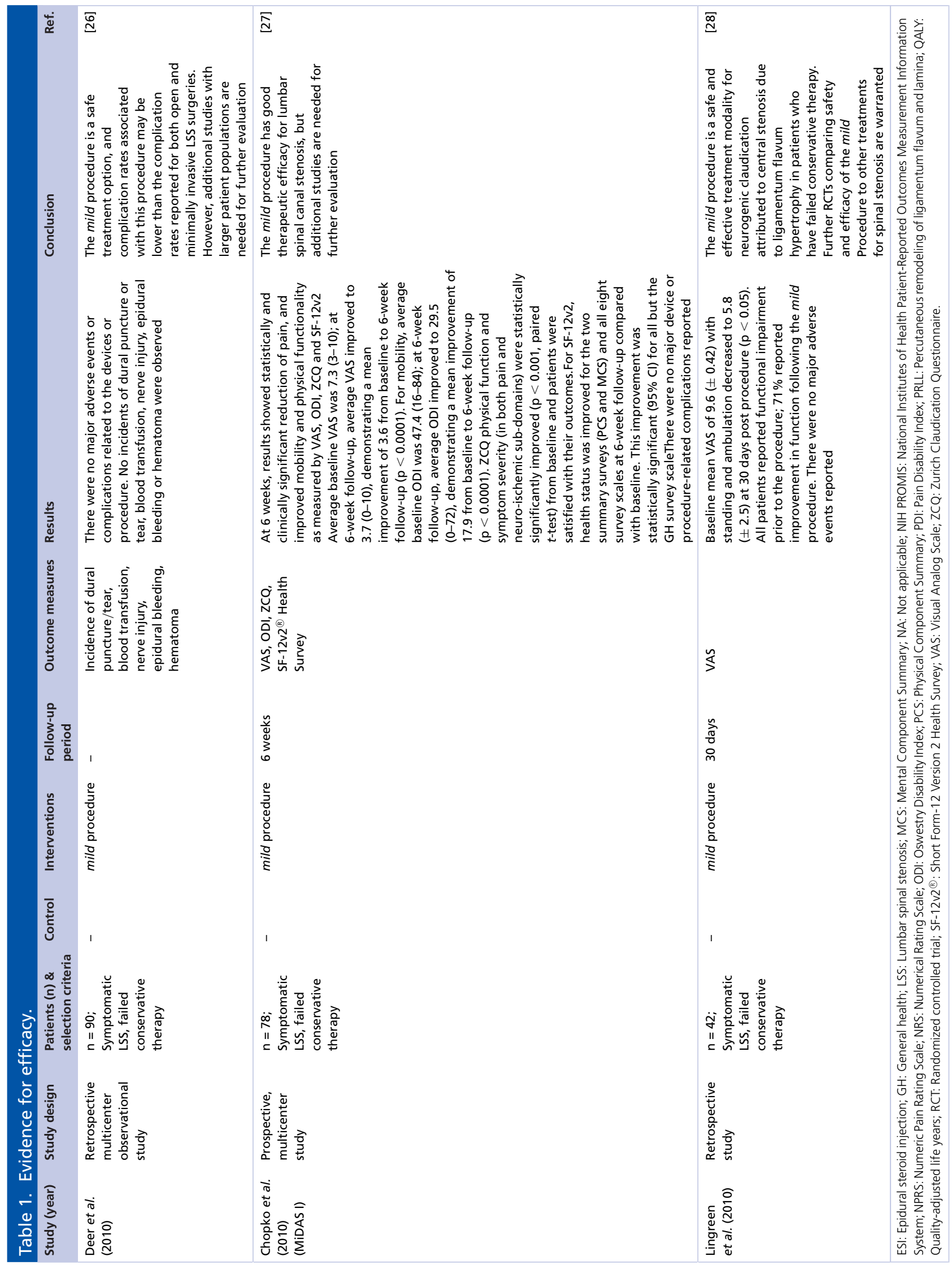




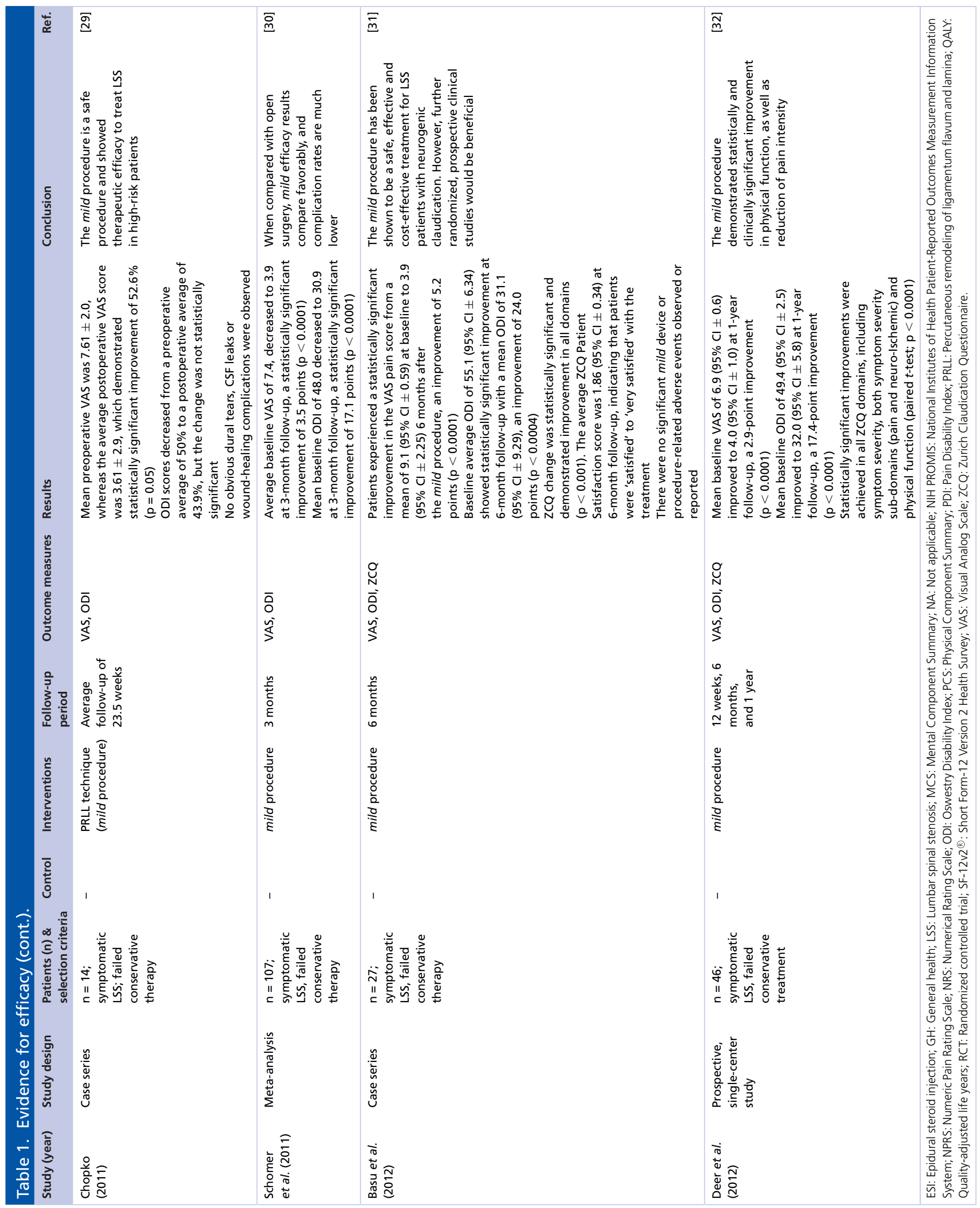




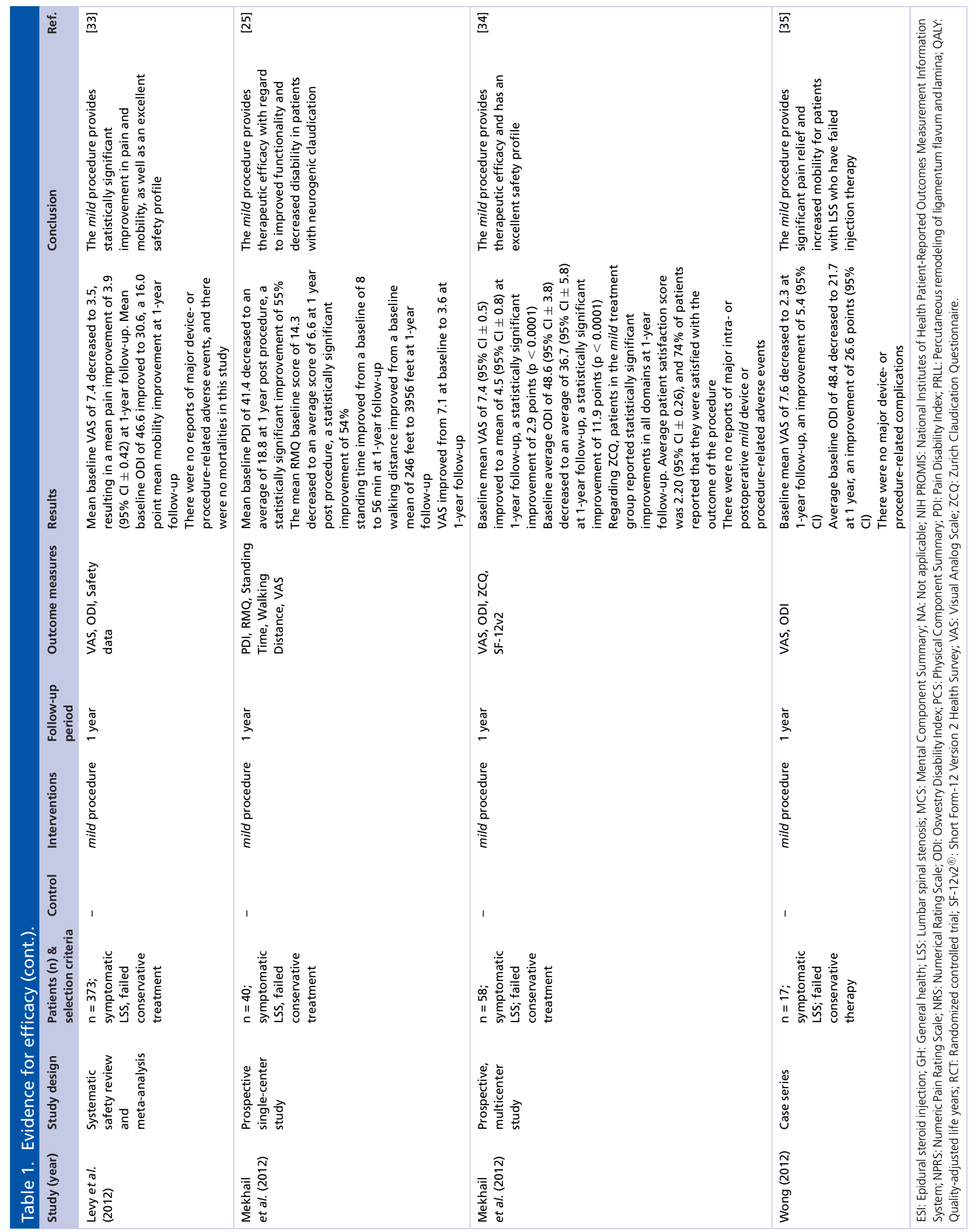




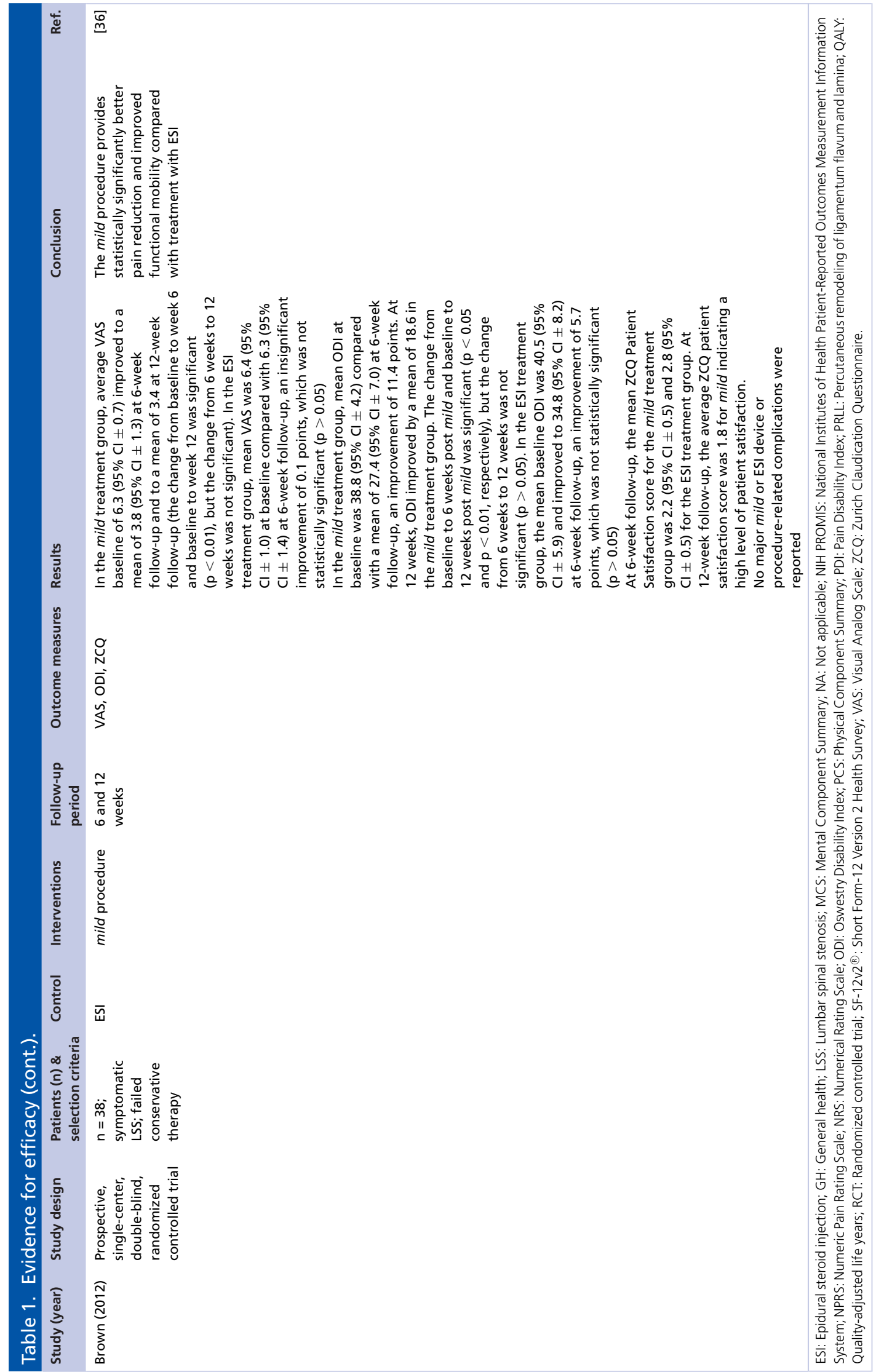




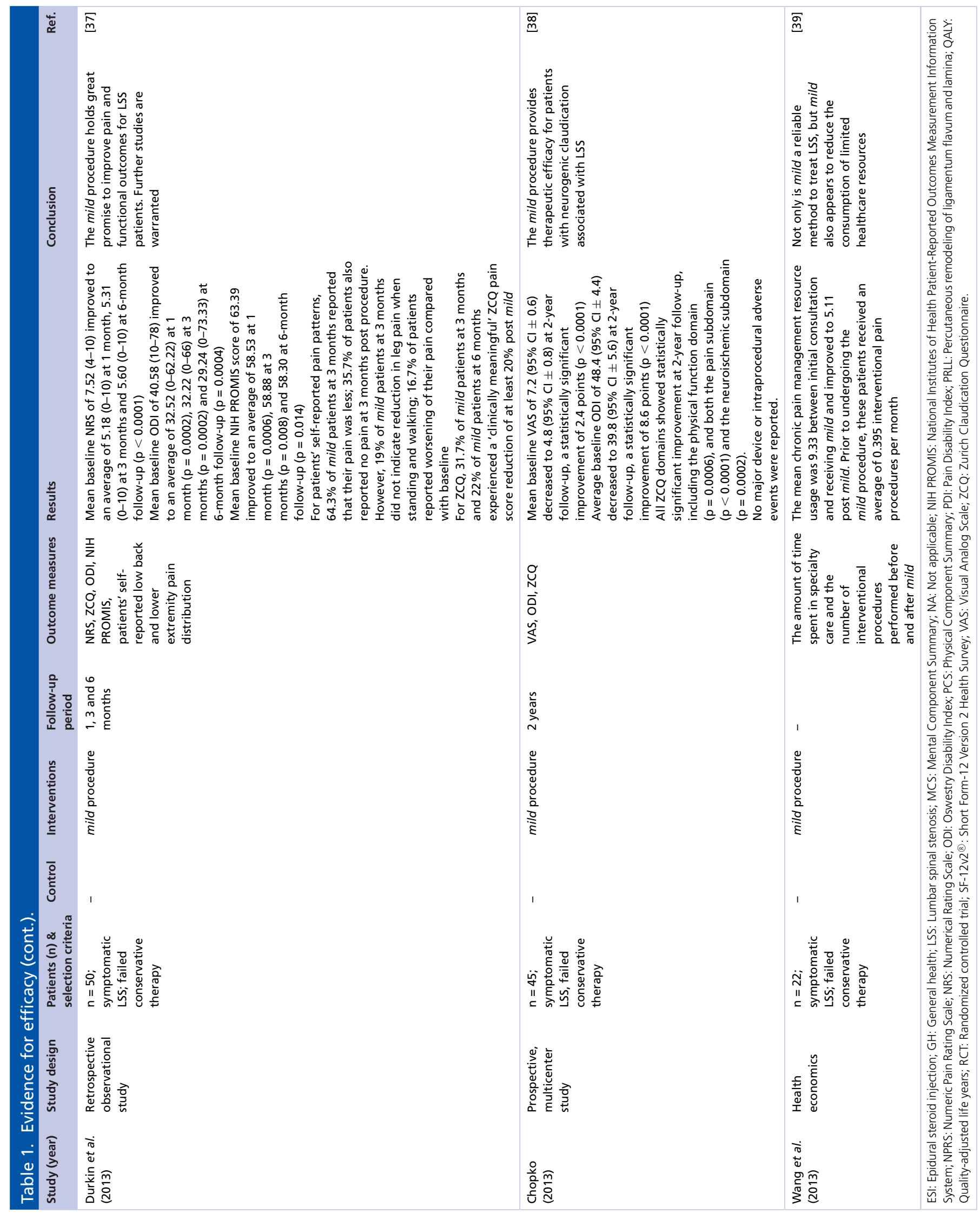




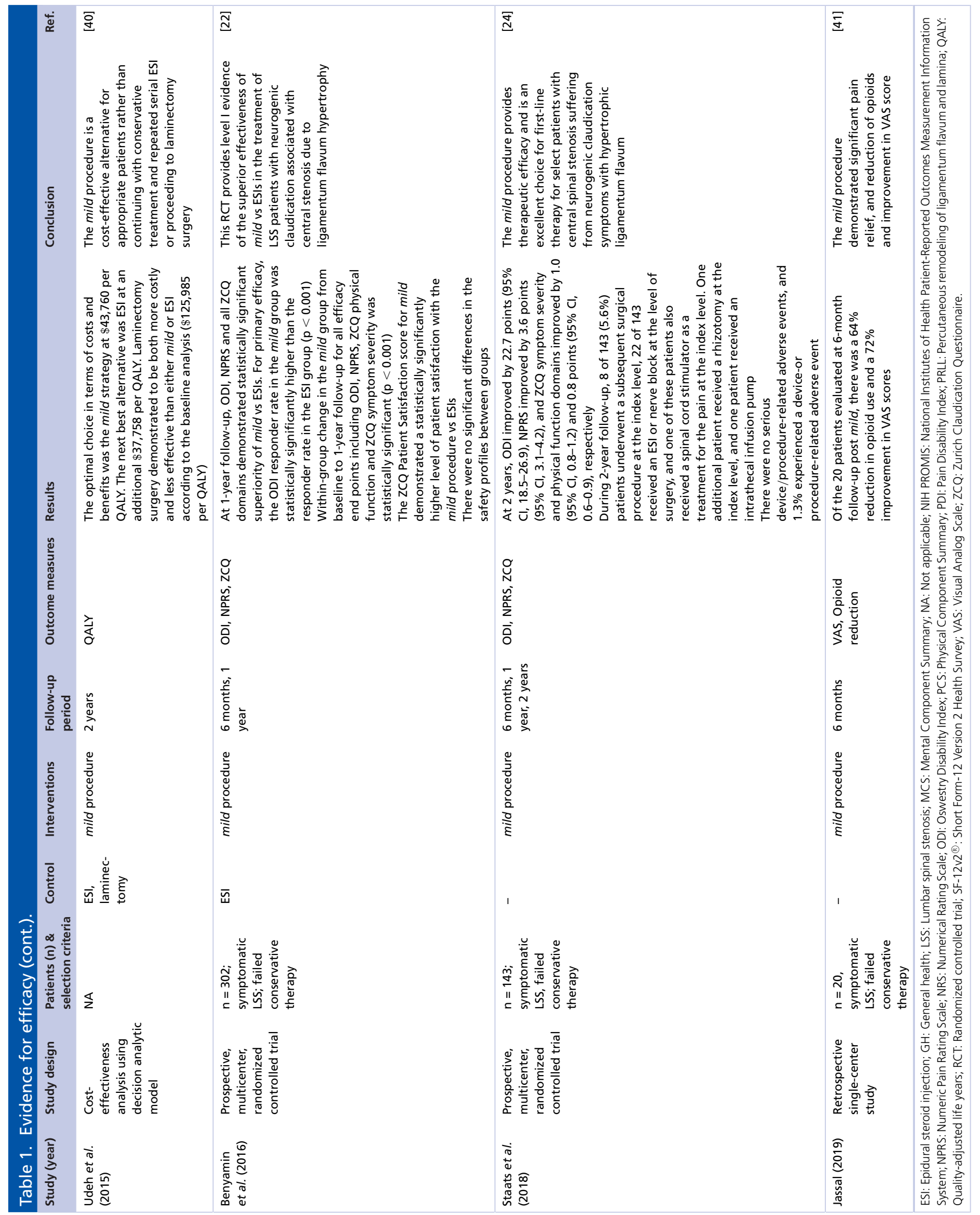


Table 2. Comparison of complications between various decompression procedures.

\begin{tabular}{|c|c|c|c|c|c|}
\hline \multirow[t]{2}{*}{ 2-year outcomes } & \multirow[t]{2}{*}{ mild $^{\dagger}$} & \multicolumn{2}{|c|}{ Interspinous process distraction } & \multirow[t]{2}{*}{ Surgical decompression $\ddagger$} & \multirow[t]{2}{*}{ Fusion $^{\S}$} \\
\hline & & Superion $\mathbb{I}$ & X-Stop ${ }^{\#}$ & & \\
\hline Reoperation & $5.6 \%$ & $20 \%$ & $14.4-26 \%$ & $6-7.8 \%$ & $12.5-16.9 \%$ \\
\hline \multirow[t]{4}{*}{ Device- and procedure-related adverse events } & $1.3 \%$ & \multicolumn{2}{|c|}{ Device } & Intraoperative: 9.9\% & $23.3 \%$ \\
\hline & & $11.6 \%$ & $7.5 \%$ & & \\
\hline & & \multicolumn{2}{|c|}{ Procedure related } & & $18 \%$ early \\
\hline & & $14.2 \%$ & $15.9 \%$ & & \\
\hline Device and procedure-related serious AEs & $0 \%$ & $8.4 \%$ & $9.5 \%$ & Postoperative: $12.3 \%$ & $6 \%$ late \\
\hline Lumbar spine fractures & $0 \%$ & $16.3 \%$ & $8.5 \%$ & - & $4.2 \%$ \\
\hline Removal of hardware & No implants & $16.3 \%$ & $12.4 \%$ & No implants & $4.3 \%$ \\
\hline $\begin{array}{l}\text { mild (Vertos Medical, CA, USA), Superion (Vertiflex, } \\
\text { †Data taken from [24]. } \\
\text { †Data taken from }[44,45] . \\
\text { ¿Data taken from }[46-50] . \\
\text { I Data taken from [51]. } \\
\text { "Data taken from [44,51]. } \\
\text { Created using data from [24]. }\end{array}$ & A), X-Stop (Meo & ic, CA, USA). & & & \\
\hline
\end{tabular}

Table 3. Comparing advantages and disadvantages of the mild procedure.

\section{Advantages}

- Broad patient selection: neurogenic claudication + ligamentum flavum

hypertrophy $(\geq 2.5 \mathrm{~mm})$ - even in patients with comorbidities

- As safe as an epidural steroid injection

- Lowest complication rate vs other lumbar spinal stenosis treatments

- Low reoperation rates

- Clinically significant long-term improvement in mobility and reduction in pain

- Minimally invasive procedure

- Intact spinal anatomy and minimal tissue trauma

- No implants

- Steroid-free procedure, thereby limiting immunosuppression risk

- No requirement for general anesthesia or hospital stay

- Resumption of normal activity within $24 \mathrm{~h}$ with no restrictions

- Maintenance of range of motion - both flexion and extension

- No contraindication for patients with osteoporosis

- No limitations regarding future interventions

- Cost effective

\section{Disadvantages \& limitations}

- Treatment of stenosis secondary to ligamentum flavum hypertrophy

- Contraindication for performing at site of previous surgery

- Some radiation exposure

does not disqualify a patient as a candidate for undergoing the mild procedure. The minimally invasive spine treatment guidelines recommend use of PILD as the first-line therapy for treatment of LSS if there is presence of $\mathrm{LFH} \geq 2.5 \mathrm{~mm}$ and absence of any contraindications, irrespective of presence/absence of other comorbidities that may contribute to spinal stenosis [9].

\section{Future perspective}

With safety and efficacy of the mild procedure well established, there has been positive growth with coverage by a national payer and self-insureds. At present, all medicare administrative contractors cover the mild procedure, an insurer that covers the age group most likely applicable for the procedure. Large self-insured plans such as Walmart's Centers of Excellence program also cover mild. Although head-to-head trials between mild and invasive surgical techniques are not permissible because the patient populations are not identical, it is important that clinical studies are conducted to build on the existing body of evidence supporting the use of this procedure versus conventional medical management. One such ongoing study is the MOTION Study (NCT03610737), which is a multicenter RCT comparing the mild procedure together with conventional medical management to conventional medical management alone in the treatment of LSS in a cohort of 150 patients [52]. The primary outcome measure of the study is the Oswestry Disability Index, along with secondary outcome measures including the Numeric Pain Rating Scale, the Zurich Claudication Questionnaire, walking distance, and walking time to symptoms. Main inclusion criteria of the study are LSS with neurogenic claudication with evidence of LFH $\geq 2.5 \mathrm{~mm}$ on imaging. Main exclusion criteria of the study are an Oswestry Disability Index Score <31, Numeric Pain Rating Scale $<5$ and prior surgery/interspinous spacer/mild procedure/vertebral augmentation/intradiscal procedure at 
the same treatment level. The estimated completion of the study is early 2022. Another ongoing study is the mild $^{\circledR}$ Percutaneous Image-Guided Lumbar Decompression: A Medicare Claims Study (NCT03072927) [53]. This is a prospective longitudinal study comparing outcomes of Medicare beneficiaries treated with mild versus those treated with interspinous process decompression at the 24-month follow-up. Primary outcome measures will include the rate of surgery or minimally invasive intervention in the patient post index procedure and the rate of participants with harms associated with the index procedure.

\section{Conclusion}

mild is a minimally invasive spine procedure for the treatment of LSS secondary to LFH that does not involve the use of implants. When used judiciously, mild has demonstrated excellent efficacy and safety in 13 peer-reviewed studies. Although treatment plans for these patients usually begin with a regimen of conservative care, subsequent treatment decisions generally favor the least invasive and safest options that may provide relief. With an established safety profile equivalent to ESIs, and efficacy that has been shown to be superior to ESIs, mild can reasonably be positioned early in the treatment algorithm for these patients. Based on extensive review of the literature, robust safety and efficacy through 2 years, and in line with the minimally invasive spine treatment guidelines, we recommend that mild be considered as the first intervention after failure of conservative measures for patients diagnosed with LSS and LFH $\geq 2.5 \mathrm{~mm}$ showing signs/symptoms of neurogenic claudication.

Financial and competing interests disclosure

This publication was supported by an unrestricted grant to the American Society of Pain \& Neuroscience (ASPN) from Vertos Medical for editorial assistance. TD: Consultant for Axonics, Bioness, Abbott, Vertos, Vertiflex, Nevro, Medtronic, CornerLoc, Nalu and SPR; minor equity interest in Stimgenics, Nalu, SPR. DS: Consultant for Flowonix, Nevro, Medtronic, SPR, PainTeq, Vertos and Vertiflex. SW: Vertos Leadership Council. The author's yearly amount received for this work does not exceed US $\$ 10 K$. NJ: Consultant/Advisory Board for Vertos, Abbott, Flowonix, CornerLoc and Medtronic. JW: Consultant for Abbott, Vertos, Medtronic, Omnia Medical and Boston Scientific; Advisory Board for Abbott. JJ: Research funding from Nevro and Boston Scientific; Consultant for Nevro, Abbott, Boston Scientific and Stimwave. MM: Consultant for Abbott, SI Bone and Nalu Medical; research for Abbott; equity interest in PrescribeFIT LLC. SG: Consultant for Abbott, Saluda and Vertos. The authors have no other relevant affiliations or financial involvement with any organization or entity with a financial interest in or financial conflict with the subject matter or materials discussed in the article apart from those disclosed.

No writing assistance was utilized in the production of this article.

\section{Open access}

This work is licensed under the Attribution-NonCommercial-NoDerivatives 4.0 Unported License. To view a copy of this license, visit http://creativecommons.org/licenses/by-nc-nd/4.0/

\section{References}

Papers of special note have been highlighted as: $\bullet$ of interest; $\bullet \bullet$ of considerable interest

1. Arnoldi CC, Brodsky AE, Cauchoix J et al. Lumbar spinal stenosis and nerve root entrapment syndromes. Definition and classification. Clin. Orthop. Relat. Res. 115, 4-5 (1976).

2. Kreiner DS, Shaffer WO, Baisden JL et al. An evidence-based clinical guideline for the diagnosis and treatment of degenerative lumbar spinal stenosis (update). Spine J. 13(7), 734-743 (2013).

3. Kalichman L, Cole R, Kim DH et al. Spinal stenosis prevalence and association with symptoms: the Framingham Study. Spine J. 9(7), 545-550 (2009).

4. Ishimoto Y, Yoshimura N, Muraki S et al. Prevalence of symptomatic lumbar spinal stenosis and its association with physical performance in a population-based cohort in Japan: the Wakayama Spine Study. Osteoarthritis Cartilage 20(10), 1103-1108 (2012).

5. Ammendolia C, Chow N. Clinical outcomes for neurogenic claudication using a multimodal program for lumbar spinal stenosis: a retrospective study. J. Manipulative Physiol. Ther. 38(3), 188-194 (2015).

6. Ammendolia C, Stuber KJ, Rok E et al. Nonoperative treatment for lumbar spinal stenosis with neurogenic claudication. Cochrane Database Syst. Rev. 8, CD010712 (2013).

7. Manchikanti L, Knezevic NN, Boswell MV, Kaye AD, Hirsch JA. Epidural injections for lumbar radiculopathy and spinal stenosis: a comparative systematic review and meta-analysis. Pain Physician 19(3), E365-E410 (2016).

8. Fukusaki M, Kobayashi I, Hara T, Sumikawa K. Symptoms of spinal stenosis do not improve after epidural steroid injection. Clin. J. Pain 14(2), 148-151 (1998). 
- A randomized study was conducted to evaluate the therapeutic effect of epidural steroid injection on neurogenic claudication in patients with lumbar spinal canal stenosis. The results indicate that epidural steroid injection has no beneficial effect on neurogenic claudication as compared with epidural block with local anesthetic alone.

9. Deer TR, Grider JS, Pope JE et al. The MIST guidelines: the Lumbar Spinal Stenosis Consensus Group guidelines for minimally invasive spine treatment. Pain Pract. 19(3), 250-274 (2019).

-. A majority of patients in the ENCORE randomized controlled trial had comorbid foraminal stenosis, facet hypertrophy or disc bulging, and these were actually a positive predictor of success with percutaneous decompression. Therefore, these comorbid findings should not be considered as a contraindication to mild. If a patient is experiencing neurogenic claudication symptoms in the presence of hypertrophic ligamentum flavum, mild should be considered first.

10. Viejo-Fuertes D, Liguoro D, Rivel J, Midy D, Guerin J. Morphologic and histologic study of the ligamentum flavum in the thoraco-lumbar region. Surg. Radiol. Anat. 20(3), 171-176 (1998).

11. Elsberg C. Experiences in spinal surgery. Surg. Gynecol. Obstet. 16, 117-132 (1913).

12. Hansson T, Suzuki N, Hebelka H, Gaulitz A. The narrowing of the lumbar spinal canal during loaded MRI: the effects of the disc and ligamentum flavum. Eur. Spine J. 18(5), 679-686 (2009).

- The ligamentum flavum (LF) contributes up to $85 \%$ of the load-induced narrowing of the spinal canal. Consequently, load-induced symptoms seemed more likely to be caused by bulging of the LF than protrusion of the disc. Given this, it is easier to understand why resection of the LF is frequently successful in relieving symptoms of neurogenic claudication.

13. Yong-Hing K, Reilly J, Kirkaldy-Willis WH. The ligamentum flavum. Spine 1(4), 226-234 (1976).

14. Chen J, Liu Z, Zhong G et al. Hypertrophy of ligamentum flavum in lumbar spine stenosis is associated with increased miR-155 level. Dis. Markers 2014, 786543 (2014).

15. Honsawek S, Poonpukdee J, Chalermpanpipat $\mathrm{C}$ et al. Hypertrophy of the ligamentum flavum in lumbar spinal canal stenosis is associated with increased bFGF expression. Int. Orthop. 37(7), 1387-1392 (2013).

16. Park JB, Chang H, Lee JK. Quantitative analysis of transforming growth factor-beta 1 in ligamentum flavum of lumbar spinal stenosis and disc herniation. Spine (Phila PA 1976) 26(21), E492-E495 (2001).

17. Hur JW, Bae T, Ye S et al. Myofibroblast in the ligamentum flavum hypertrophic activity. Eur. Spine J. 26(8), 2021-2030 (2017).

18. Jirathanathornnukul N, Limthongkul W, Yingsakmongkol W, Singhatanadgige W, Parkpian V, Honsawek S. Increased expression of vascular endothelial growth factor is associated with hypertrophic ligamentum flavum in lumbar spinal canal stenosis. J. Investig. Med. 64(4), 882-887 (2016).

19. Malfair D, Beall DP. Imaging the degenerative diseases of the lumbar spine. Magn. Reson. Imaging Clin. N. Am. 15(2), 221-238 (2007).

20. Siebert E, Pruss H, Klingebiel R, Failli V, Einhaupl KM, Schwab JM. Lumbar spinal stenosis: syndrome, diagnostics and treatment. Nat. Rev. Neurol. 5(7), 392-403 (2009).

21. Abbas J, Hamoud K, Masharawi YM et al. Ligamentum flavum thickness in normal and stenotic lumbar spines. Spine (Phila PA 1976) 35(12), 1225-1230 (2010).

22. Benyamin RM, Staats PS. mild ${ }^{\circledR}$ is an effective treatment for lumbar spinal stenosis with neurogenic claudication: MiDAS ENCORE Randomized Controlled Trial. Pain Physician 19(4), 229-242 (2016).

-• One-year follow-up of the ENCORE level 1 randomized controlled trial demonstrated statistical superiority of mild efficacy versus epidural steroid injections in the treatment of lumbar spinal stenosis patients with neurogenic claudication and ligamentum flavum hypertrophy. mild was also shown to be as safe as epidural steroid injections.

23. Steurer J, Roner S, Gnannt R, Hodler J. . Quantitative radiologic criteria for the diagnosis of lumbar spinal stenosis: a systematic literature review. BMC Musculoskelet. Disord. 12, 175 (2011).

24. Staats PS, Chafin TB, Golovac S et al. Long-term safety and efficacy of minimally invasive lumbar decompression procedure for the treatment of lumbar spinal stenosis with neurogenic claudication: 2-year results of MiDAS ENCORE. Reg. Anesth. Pain Med. 43(7), 789-794 (2018).

-. mild showed excellent long-term durability through 2 years. Given the minimally invasive nature of this procedure, as well as its robust success rate, strong safety record and durability of outcomes, mild is an excellent choice for first-line therapy.

25. Mekhail N, Costandi S, Abraham B, Samuel SW. Functional and patient-reported outcomes in symptomatic lumbar spinal stenosis following percutaneous decompression. Pain Pract. 12(6), 417-425 (2012).

-• This study demonstrated statistically significant functional improvement as measured by Standing Time and Walking Distance at 1 year after the mild procedure. Standing Time improved 7-fold from a baseline mean of 8 min to 56 min at 1 year. Walking Distance improved 16-fold from a mean of 246 feet to 3,956 feet at 1 year.

26. Deer TR, Kapural L. New image-guided ultra-minimally invasive lumbar decompression method: the mild procedure. Pain Physician 13(1), 35-41 (2010).

27. Chopko B, Caraway DL. MiDAS I (mild Decompression Alternative to Open Surgery): a preliminary report of a prospective, multi-center clinical study. Pain Physician 13(4), 369-378 (2010). 
28. Lingreen R, Grider JS. Retrospective review of patient self-reported improvement and post-procedure findings for mild (minimally invasive lumbar decompression). Pain Physician 13(6), 555-560 (2010).

29. Chopko BW. A novel method for treatment of lumbar spinal stenosis in high-risk surgical candidates: pilot study experience with percutaneous remodeling of ligamentum flavum and lamina. J. Neurosurg. Spine 14(1), 46-50 (2011).

30. Schomer DF, Solsberg D, Wong W, Chopko BW. mild ${ }^{\circledR}$ lumbar decompression for the treatment of lumbar spinal stenosis. Neuroradiol. J. 24(4), 620-626 (2011).

31. Basu S. mild procedure: single-site prospective IRB study. Clin. J. Pain 28(3), 254-258 (2012).

32. Deer TR, Kim CK, Bowman RG 2nd, Ranson MT, Yee BS. Study of percutaneous lumbar decompression and treatment algorithm for patients suffering from neurogenic claudication. Pain Physician 15(6), 451-460 (2012).

33. Levy RM, Deer TR. Systematic safety review and meta-analysis of procedural experience using percutaneous access to treat symptomatic lumbar spinal stenosis. Pain Med. 13(12), 1554-1561 (2012).

34. Mekhail N, Vallejo R, Coleman MH, Benyamin RM. Long-term results of percutaneous lumbar decompression mild ${ }^{\circledR}$ for spinal stenosis. Pain Pract. 12(3), 184-193 (2012).

35. Wong WH. mild interlaminar decompression for the treatment of lumbar spinal stenosis: procedure description and case series with 1-year follow-up. Clin. J. Pain 28(6), 534-538 (2012).

36. Brown LL. A double-blind, randomized, prospective study of epidural steroid injection vs. the mild ${ }^{\circledR}$ procedure in patients with symptomatic lumbar spinal stenosis. Pain Pract. 12(5), 333-341 (2012).

- This double-blind, randomized controlled trial of epidural steroid injection vs the mild procedure produced level 1 evidence that mild provides statistically significantly better pain reduction and improved functional mobility versus treatment with epidural steroid injection.

37. Durkin B, Romeiser J, Shroyer AL et al. Report from a quality assurance program on patients undergoing the mild procedure. Pain Med. 14(5), 650-656 (2013).

38. Chopko BW. Long-term results of percutaneous lumbar decompression for LSS: two-year outcomes. Clin. J. Pain 29(11), 939-943 (2013).

39. Wang JJ, Bowden K, Pang G, Cipta A. Decrease in health care resource utilization with mild. Pain Med. 14(5), 657-661 (2013).

40. Udeh BL, Costandi S, Dalton JE, Ghosh R, Yousef H, Mekhail N. The 2-year cost-effectiveness of 3 options to treat lumbar spinal stenosis patients. Pain Pract. 15(2), 107-116 (2015).

- Using a decision-analytic model from the Medicare perspective, a cost-effectiveness analysis was performed comparing mild to epidural steroid injection or laminectomy surgery. mild was the most cost effective ( $\$ 43,760$ /quality-adjusted life years [QALY]), with epidural steroid injection the next best alternative at an additional $\$ 37,758 /$ QALY. Laminectomy surgery was the least cost effective $(\$ 125,985 /$ QALY).

41. Jassal N. Single center experience of mild procedure evaluating opioid and pain reduction at follow up. Presented at: American Society of Interventional Pain Physicians (ASIPP) Annual Meeting. NV, USA, 3-5 May 2019.

42. Choy DS, Ascher PW, Ranu HS et al. Percutaneous laser disc decompression. A new therapeutic modality. Spine (Phila Pa 1976) 17(8), 949-956 (1992).

43. Cho JH, Hwang CJ, Kim H, Joo YS, Lee DH, Lee CS. Effect of osteoporosis on the clinical and radiological outcomes following one-level posterior lumbar interbody fusion. J. Orthop. Sci. 23(6), 870-877 (2018).

44. Stromqvist $\mathrm{BH}$, Berg $\mathrm{S}$, Gerdhem $\mathrm{P}$ et al. X-stop versus decompressive surgery for lumbar neurogenic intermittent claudication: randomized controlled trial with 2-year follow-up. Spine (Phila Pa 1976) 38(17), 1436-1442 (2013).

45. Weinstein JN, Tosteson TD, Lurie JD et al. Surgical versus nonsurgical therapy for lumbar spinal stenosis. N. Engl. J. Med. 358(8), 794-810 (2008).

46. Irmola TM, Hakkinen A, Jarvenpaa S, Marttinen I, Vihtonen K, Neva M. Reoperation rates following instrumented lumbar spine fusion. Spine (Phila Pa 1976) 43(4), 295-301 (2018).

47. Försth P, Ólafsson G, Carlsson T et al. A randomized, controlled trial of fusion surgery for lumbar spinal stenosis. N. Engl. J. Med. 374, 1413-1423 (2016).

48. Choi JM, Choi MK, Kim SB. Perioperative results and complications after posterior lumbar interbody fusion for spinal stenosis in geriatric patients over than 70 years old. J. Korean Neurosurg. Soc. 60(6), 684-690 (2017).

49. Ong KL, Auerbach JD, Lau E, Schmier J, Ochoa JA. Perioperative outcomes, complications, and costs associated with lumbar spinal fusion in older patients with spinal stenosis and spondylolisthesis. Neurosurg. Focus 36(6), E5 (2014).

50. Swedish Lumbar Spine Study Group. Fritzell P, Hagg O, Wessberg P, Nordwall A. 2001 Volvo Award Winner in Clinical Studies: lumbar fusion versus nonsurgical treatment for chronic low back pain: a multicenter randomized controlled trial from the Swedish Lumbar Spine Study Group. Spine (Phila PA 1976) 26(23), 2521-2532 (2001).

51. FDA. Superion ${ }^{\circledR}$ InterSpinous Spacer summary of safety $\&$ effectiveness data. (2015). www.accessdata.fda.gov/cdrh_docs/pdf14/P140004b.pdf 
Review Jain, Deer, Sayed et al.

52. ClinicalTrials.gov. The MOTION study - treatment of LSS with the mild procedure. (2020). https://clinicaltrials.gov/ct2/show/NCT03610737?term=vertos\&draw=3\&rank=7

53. ClinicalTrials.gov. mild ${ }^{\circledR}$ percutaneous image-guided lumbar decompression: a Medicare claims study. (2020). https://clinicaltrials.gov/ct2/show/study/NCT03072927?term=vertos\&draw=4\&rank=11\#locn 